\title{
Isolation of Tiliroside from Spiranthera odoratissima as Inhibitor of Trypanosoma cruzi Glyceraldehyde-3-phosphate Dehydrogenase by Using Bioactivity-Guided Fractionation
}

\author{
Vivian E. Cornelio, ${ }^{a}$ Fernando V. Maluf, ${ }^{b}$ João B. Fernandes, ${ }^{a}$ Maria Fátima G. F. da \\ Silva, ${ }^{a}$ Glaucius Oliva, ${ }^{b}$ Rafael V. C. Guido ${ }^{b}$ and Paulo C. Vieira*,a \\ ${ }^{a}$ Laboratório de Química de Produtos Naturais, Departamento de Química, Universidade Federal \\ de São Carlos, 13565-905 São Carlos-SP, Brazil \\ ${ }^{b}$ Instituto de Física de São Carlos, Universidade de São Paulo, CP 369, \\ 13560-970 São Carlos-SP, Brazil
}

\begin{abstract}
Glyceraldehyde-3-phosphate dehydrogenase (GAPDH) is a key enzyme involved in the Trypanosoma cruzi glycolytic pathway, parasite that causes Chagas' disease. There are only few drugs available to treat this disease, most of which present strong side effects. Natural products constitute a prime source for the discovery of new scaffolds potentially useful for the treatment of several diseases, including Chagas' disease. Bioactivity-guided fractionation of Spiranthera odoratissima extract using T. cruzi GAPDH (TcGAPDH) as a target led to the isolation of the flavonoid tiliroside (kaempferol-3-O- $\beta$-D-(6"-trans- -coumaroyl)-glucopyranoside), identified as an excelent inhibitor of this enzyme and for the first time reported for this plant species. Mechanistic studies of tiliroside showed that it is a reversible non-competitive inhibitor of TcGAPDH. In additon, molecular modeling analysis indicated the binding mode of tiliroside to TcGAPDH. Therefore, the identification of tiliroside as TcGPADH inhibitor in a complex matrix such as the plant crude extract and the discovery of a new binding site may contribute to the opening of new paths in the search for natural product inhibitors of this enzyme.
\end{abstract}

Keywords: glyceraldehyde-3-phosphate dehydrogenase, GAPDH, tiliroside, kaempferol-3O- $\beta$-D-(6"-trans-p-coumaroyl)-glucopyranoside, Spiranthera odoratissima, bioactivity-guided fractionation

\section{Introduction}

In 1909 the Brazilian physician Carlos Chagas first described the disease that now bears his name. ${ }^{1}$ Today, it is estimated that this disease, caused by the protozoan parasite Trypanosoma cruzi (T. cruzi), infects 7-8 million people, mostly in Latin America. However, in the past decades it has been increasingly detected in the United States of America, Canada, many European and some Western Pacific countries. ${ }^{2-4}$ There are only few drugs to treat Chagas' disease in humans, including nifurtimox and benzonidazole. However, these drugs have a limited efficacy and strong side effects. ${ }^{5}$ Therefore, there are considerable efforts to discover new treatments for Chagas disease. $^{6}$

\footnotetext{
*e-mail: dpcv@ufscar.br
}

Glyceraldehyde-3-phosphate dehydrogenase (GAPDH, EC 1.2.1.12) is a key enzyme involved in T. cruzi's glycolytic pathway. ${ }^{7}$ The presence of glycosome, a specialized glycolytic organelle in Trypanosoma and Leishmania, suggested an opportunity for the development of selective inhibitors. ${ }^{6,8}$ In fact, the GAPDH has received considerable attention since it became a validated potential target for inhibitor discovery. ${ }^{89}$ Moreover, human GAPDH has emerged as an attractive target for anticancer therapy. ${ }^{10}$ This homotetrameric enzyme catalyzes the oxidative phosphorylation of D-glyceraldehyde-3-phosphate (G-3-P) to 1,3-diphosphoglycerate (1,3-DPGA) in presence of $\mathrm{NAD}^{+}$and inorganic phosphate. ${ }^{11}$ Few known smallmolecule inhibitors of this enzyme include bioactive natural products such as coumarins, ${ }^{12,13}$ anacardic acids, flavonoids and glucosylxanthone derivatives, ${ }^{14,15}$ geranylated benzophenone derivatives, ${ }^{16}$ and 3-bromo-isoxazoline derivatives. ${ }^{17,18}$ 
Nature, in some way and until now, has affected the design of small molecules and natural products and/or natural product structures remain to play a highly significant role in the drug discovery. ${ }^{19} \mathrm{New}$ tools in separation, purification and high throughput screening ${ }^{20}$ have encouraged the drug discovery from natural sources, and one these approaches is the bioactivity-guided fractionation. ${ }^{21}$

Spiranthera odoratissima A. St.-Hil. (Rutaceae family), known as "Manacá", is popularly used for the treatment of rheumatism, gout, acne, boils, kidney infection and inflammation in general. ${ }^{22}$ There are also studies of Spiranthera odoratissima extracts concerning analgesic and anti-inflammatory activity, ${ }^{23,24}$ assays against Plasmodium falciparum FcB1 strain, Leishmania (L.) chagasi, Trypanosoma cruzi and NIH-3T3 mammalian cells ${ }^{25,26}$ and against leaf-cutting ants and their symbiotic fungus. ${ }^{27}$ From the phytochemical viewpoint, this plant has shown to contain coumarins (auraptene, osthol and braylin), furoquinoline alkaloids (dictamnine, $\gamma$-fagarine and skimmianine), $\beta$-indoloquinazoline alkaloids (rutaecarpine, evodiamine and 1-hydroxyrutaecarpine) 2-arylquinoli-4-one alkaloid, limonoids (limonexic acid and limonin), monoterpenes (pinene, limonene, mircene), sesquiterpenes (copaene, germacrene, caryophyllene, espatulenol, caryophyllene oxide and $\beta$-sitosterol)..$^{27-29}$

During our current investigations toward the discovery of new GAPDH inhibitors, we observed that the extract of $S$. odoratissima displayed inhibitory activity on TcGAPDH. Bioassay-guided fractionation of this extract led to the isolation of tiliroside (kaempferol-3-O- $\beta$-D-(6"trans-p-coumaroyl)-glucopyranoside). Herein we present the TcGAPDH-inhibitory activity profile of tiliroside, including its mechanism-of-action and molecular docking analysis, aiming to unveil tiliroside activity as a GAPDH inhibitor.

\section{Experimental}

\section{General experimental procedures}

The 1D and 2D nuclear magnetic resonance (NMR) data were acquired on a Bruker DRX-400 NMR spectrometer $\left({ }^{1} \mathrm{H}: 400 \mathrm{MHz} ;{ }^{13} \mathrm{C}\right.$ : $\left.100 \mathrm{MHz}\right)$ using DMSO- $d_{6}$ and $\mathrm{MeOH}-d_{4}$ as solvents. Sephadex® LH-20 (Amersham Pharmacia Biotech $\mathrm{AB}$ ) was used to isolate the compounds and thin-layer chromatography (TLC) on pre-coated aluminum silica 60 F254 (Merck) was used to analyze the fractions. Compounds were visualized in TLC UV 254/366 and by the usage of the stain sulfuric vanillin solution. The solvents ethanol (EtOH), methanol $(\mathrm{MeOH})$, hexane, acetone, ethyl acetate (EtOAc) and dichloromethane from J. T. Baker were used to prepare the extracts and for chromatographic procedures.

Plant material

S. odoratissima stems were collected at Rio Verde, Jataí, in January 2001. The identification was carried out by Dr José Rubens Pirani from the Department of Botany, São Paulo University and voucher is deposited in the Herbarium of the same department (voucher No. 4778).

\section{Extraction and isolation of compounds}

Ethanol extracts were prepared by maceration of airdried and powdered plant parts from different species of Rutaceae family. The crude extracts were obtained after removal of the solvents by rotatory evaporation under reduced pressure at a temperature of $40{ }^{\circ} \mathrm{C}$. Dried extracts were submitted to enzymatic assays against TcGAPDH (Figure S1). As S. odoratissima presented the most promising inhibition, bioactivity-guided fractionation of the crude ethanolic extract from the stems $(27.0 \mathrm{~g})$ was initiated by liquid-liquid partition into hexane $(3.5 \mathrm{~g})$, $\mathrm{CH}_{2} \mathrm{Cl}_{2}(4.0 \mathrm{~g})$, EtOAc (2.5 g) and hydroalcoholic (15.0 g) extracts, however only EtOAc and hydroalcoholic extracts showed significant inhibitory activity against TcGAPDH (Figure S2). The stem EtOAc extract was fractionated on a Sephadex ${ }^{\circledR}$ LH 20 column $(70.0 \times 3.5 \mathrm{~cm} ; \mathrm{MeOH})$, affording 10 fractions (SG1-SG10). Among them, SG9 $(53 \mathrm{mg})$ and SG10 $(27 \mathrm{mg})$, with 97 and $94 \%$ of TcGAPDH inhibition, respectively, were chromatographed over Sephadex ${ }^{\circledR}$ LH 20 column $(55.0 \times 2.5 \mathrm{~cm} ; \mathrm{MeOH})$, leading to the isolation of flavonoid kaempferol-3-O- $\beta$ $\mathrm{D}$-(6"-trans-p-coumaroyl)-glucopyranoside (tiliroside) (10 mg) (Figure 2), monitored by TLC and NMR. The isolated compound was characterized by NMR $\left({ }^{1} \mathrm{H}\right.$ and ${ }^{13} \mathrm{C}$, distortionless enhancement by polarization transfer (DEPT-135), heteronuclear single quantum correlation (HSQC), and heteronuclear multiple bond correlation (HMBC)) and compared with data published in the literature $^{30}$ (Figures S3 to S7).

\section{Cloning, expression and purification of GAPDH}

The open reading frame (ORF) encoding glycosomal glyceraldehyde 3-phosphate was amplified from Trypanosoma cruzi using the primers GAPDH LIC_Fw (CAGGGCGCCATGCCCATCAAGGTCG) and GAPDH_LIC_Rv (GACCCGACGCGGTTA CAACCTTGCCGAACG). The fragment was cloned 
into expression vector pET-Trx1a/LIC by LIC (ligation independent cloning), as described elsewhere. ${ }^{31}$ The recombinant plasmid was amplified in $\mathrm{DH} 5 \alpha$ E. coli, and the gene sequence verified, before being transformed into Rosetta (DE3) E. coli for protein production. The E. coli containing the full-length His-tagged TcGAPDH plasmid was culture at $37^{\circ} \mathrm{C}$ with shaking at $150 \mathrm{rpm}$ in Luria Bertami (LB) media supplemented with $50 \mu \mathrm{g} \mathrm{mL}^{-1}$ kanamycin and $34 \mu \mathrm{g} \mathrm{mL}^{-1}$ chloramphenicol until an $\mathrm{OD}_{600 \mathrm{~mm}}$ of 0.6. Next, $0.4 \mathrm{mmol} \mathrm{L}^{-1}$ IPTG (isopropyl- $\beta$-D-thiogalactoside) was added to the culture which was grown for additional $16 \mathrm{~h}$ at $20^{\circ} \mathrm{C}$. The cells were harvest by centrifugation $\left(3.500 \mathrm{~g}, 30 \mathrm{~min}, 4^{\circ} \mathrm{C}\right)$ and re-suspended in lysis buffer (50 mmol L $\mathrm{L}^{-1}$ Tris- $\mathrm{HCl} \mathrm{pH} \mathrm{8.0,} 500 \mathrm{mmol} \mathrm{L}^{-1} \mathrm{NaCl}$ and $20 \mathrm{mmol} \mathrm{L}^{-1}$ imidazole) containing Benzonase $5 \mathrm{U} \mathrm{mL}^{-1}$, DTT $1 \mathrm{mmol} \mathrm{L}^{-1}$ and protease inhibitors $\left(1 \mathrm{mmol} \mathrm{L}^{-1} \mathrm{PMSF}\right.$, $2 \mu \mathrm{g} \mathrm{mL}^{-1}$ pepstatin, $5 \mu \mathrm{g} \mathrm{mL}^{-1}$ leupeptin). The cells were lysed by sonication ( 16 cycles of $30 \mathrm{~s}$ burst at $200 \mathrm{~W}$ with $30 \mathrm{~s}$ cooling period between each burst) on ice and the insoluble debris separated by centrifugation $(20.000 \mathrm{~g}$, $\left.30 \mathrm{~min}, 4{ }^{\circ} \mathrm{C}\right)$. The soluble fraction was filtered $(0.45 \mu \mathrm{m})$ and loaded onto a HisTrap HP $5 \mathrm{~mL}$ (GE Healthcare). His-tagged protein was eluted with a $0-500 \mathrm{mmol} \mathrm{L}^{-1}$ imidazole gradient. HiTrap Desalting (GE Healthcare) was used in order to remove imidazole. 6xHis-Trx tag was removed by overnight digestion with TEV (Tobacco Etch Virus) at $4{ }^{\circ} \mathrm{C}$, and re-purified by second passage through HisTrap HP $5 \mathrm{~mL}$. The sample of TcGAPDH was concentrated then applied to Superdex 200, 16/60 column (GE Healthcare), pre-equilibrated with $50 \mathrm{mmol} \mathrm{L}^{-1}$ Tris- $\mathrm{HCl} \mathrm{pH}$ 8.0, $200 \mathrm{mmol} \mathrm{L}^{-1} \mathrm{NaCl}$ buffer. Protein concentration was determined spectrophotometrically using a theoretical extinction coefficient $39,880 \mathrm{~mol} \mathrm{~L}^{-1} \mathrm{~cm}^{-1}$ at $280 \mathrm{~nm}$ calculated using ProtParam..$^{32}$ The high level of purity obtained after the last purification step was confirmed by sodium dodecyl sulfate polyacrylamide gel electrophoresis (SDS-PAGE) .

\section{Enzyme kinetic assay}

Kinetic measurements were carried out spectrophotometrically with SpectraMax ${ }^{\circledR}$ Plus384 absorbance microplate reader spectrophotometer, using a standard assay as previously described.$^{33}$ All enzymatic assays were carried out in triplicate at $25{ }^{\circ} \mathrm{C}$ in clear, flat bottom, polystyrene 96-well plate. The reaction mixture contained $20 \mathrm{nmol} \mathrm{L}^{-1} \mathrm{TcGAPDH}, 100 \mathrm{mmol} \mathrm{L}^{-1}$ triethanolamine-HCl buffer $(\mathrm{pH} 7.5), 1 \mathrm{mmol} \mathrm{L}^{-1}$ EDTA, $1 \mathrm{mmol} \mathrm{L}{ }^{-1} \beta$-mercaptoethanol, $30 \mathrm{mmol} \mathrm{L}^{-1}$ sodium arsenate, $250 \mu \mathrm{mol} \mathrm{\textrm {L } ^ { - 1 }}$ thionicotinamide adenine dinucleotide oxidized form $\left(\mathrm{T}-\mathrm{NAD}^{+}\right)$, and $800 \mu \mathrm{mol} \mathrm{L}^{-1}$ glyceraldehyde-3-phosphate (G3P). The final reaction volume was $200 \mu \mathrm{L}$. The biochemical reduction of $\mathrm{T}^{-\mathrm{NAD}^{+}}$to T-NADH was monitored at $400 \mathrm{~nm}$ for $10 \mathrm{~min}$. Compounds were dissolved in 100\% DMSO and incubated with the reaction mixture for $10 \mathrm{~min}$. The final concentration of DMSO in the reaction mixture not exceed $10 \%(\mathrm{v} / \mathrm{v})$. The percentage of inhibition was calculated according to the following equation:

$\%$ of inhibition $=100 \times\left(1-\mathrm{V}_{\mathrm{i}} / \mathrm{V}_{0}\right)$

where, $\mathrm{V}_{\mathrm{i}}$ and $\mathrm{V}_{0}$ are the initial velocities determined in the presence and absence of inhibitor, respectively. Iodoacetic acid, a known TcGAPDH inhibitor, ${ }^{34}$ at $200 \mu \mathrm{mol} \mathrm{L}^{-1}$ was used as positive control for enzyme inhibition.

No precipitation of the active or inactive compounds was observed in the reaction mixtures. Promiscuous inhibition caused by aggregate-forming inhibitors with the target protein was evaluated by measuring the enzyme inhibition in the presence of the non-ionic surfactant Triton $\mathrm{X}-100 .{ }^{35}$ Kinetic measurements were conducted with addition of Triton X-100 to final concentration of $0.01 \%$ $(\mathrm{v} / \mathrm{v})$ to reaction mixture before ligand incubation.

The compounds with significant inhibition have had the $\mathrm{IC}_{50}$ values determined. $\mathrm{IC}_{50}$ values were independently determined by making rate measurements for at least six inhibitor concentrations. All kinetic parameters were determined from the collected data by nonlinear regression employing the SigmaPlot enzyme kinetics module. The values represent means of at least three individual experiments.

\section{Results and Discussion}

Initially, extracts from several species from Rutaceae family were evaluated against TcGAPDH, however Spiranthera odoratissima ethanolic crude extract (SOGE) showed the most promising results, with inhibition higher than $60 \%$ at a concentration of $200 \mu \mathrm{g} \mathrm{mL}^{-1}$ (Figure S1). The percentage of inhibition was calculated according to the equation 1. Based on bioactivity-guided fractionation strategy (Figure 1), liquid extraction of this ethanolic crude extract led to obtain, among others, the ethyl acetate fraction (SOG-PAC), which showed 74\% of inhibition (Figure S2). Phytochemical study and subsequent fractioning of the EtOAc extract led to the isolation of active known compound kaempferol-3-O- $\beta$-D-(6"-trans-p-coumaroyl)glucopyranoside (tiliroside) (Figure 2), for first time reported in Spiranthera odoratissima.

For the enzymatic assays we expressed recombinant TcGAPDH in E. coli and purified it to homogeneity by 


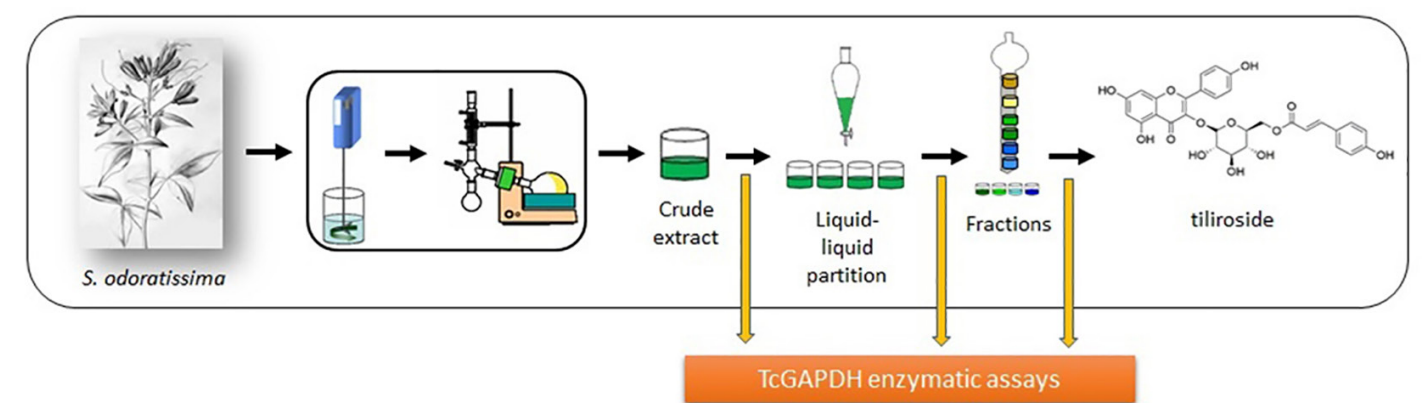

Figure 1. Bioactivity-guided TcGAPDH assays used for fractionation of Spiranthera odoratissima leading to isolation of tiliroside (S. odoratissima picture adapted from reference 36 ).<smiles>O=C(/C=C/c1ccc(O)cc1)OC[C@H]1O[C@@H](Oc2c(-c3ccc(O)cc3)oc3cc(O)cc(O)c3c2=O)[C@H](O)[C@H](O)[C@@H]1O</smiles>

Figure 2. Structure of compound kaempferol-3-O- $\beta$-D- $(6 "$-trans$p$-coumaroyl)-glucopyranoside (tiliroside) isolated from steams of Spiranthera odoratissima extract.

chromatographic methods to evaluate the capacity of the enzyme to bind tiliroside in vitro. The strategy to purify the protein included a combination of affinity and size-exclusion chromatography. We identified a single symmetric peak related to pure and folded tetrameric 156-kDa protein in the gel filtration column (Figure 3A). Next, to evaluate the inhibitory activity of tiliroside on recombinant purified TcGAPDH (Figure 3B) we employed enzymatic assay using ultraviolet-visible (UV-Vis) spectroscopy based-method. The dose response curve suggests a concentration-depended inhibition with an $\mathrm{IC}_{50}$ value of $22 \pm 2 \mu \mathrm{M}$ (Figure 3C). Moreover, we studied the effectiveness of tiliroside as TcGAPDH inhibitor by assessing the mechanism of inhibition. In this investigation, tiliroside concentration was fixed at 5,10 , and $20 \mu \mathrm{M}$ and the TcGAPDH inhibition was evaluated in the presence of increasing doses of both substrate and cofactor (G3P and $\mathrm{TNAD}^{+}$, respectively). Figures $3 \mathrm{D}$ and $3 \mathrm{E}$ indicate that both $\mathrm{V}_{\max }$ and $\mathrm{K}_{\mathrm{M}}$ app (defined as the substrate concentration at which half maximum velocity of reaction is observed under given set of conditions) values change as a function of inhibitor increasing concentrations. This observation is typical of non-competitive inhibitor (Figure 3F). Therefore, tiliroside does not act as an active site inhibitor and binds to both the free (E) and the enzyme-substrate complex (ES) forms of the enzyme, with slightly higher affinity for the free-form of TcGAPDH $\left(\mathrm{K}_{\mathrm{i}}^{\mathrm{G} 3 \mathrm{P}}=9 \mu \mathrm{M} ; \mathrm{K}_{\mathrm{i}}{ }^{\mathrm{G} 3 \mathrm{P}}=11 \mu \mathrm{M}\right.$ and $\mathrm{K}_{\mathrm{i}}{ }^{\mathrm{TNAD}}=14 \mu \mathrm{M} ; \mathrm{K}{ }_{\mathrm{i}}{ }^{\mathrm{TNAD}}=15 \mu \mathrm{M}$; where $\mathrm{K}_{\mathrm{i}}{ }^{\mathrm{G} 3 \mathrm{P}}$ is the dissociation constant for the binary enzyme-inhibitor complex obtained in the presence of the substrate G3P; $\mathrm{K}_{\mathrm{i}}{ }_{\mathrm{G}}^{\mathrm{G} P \mathrm{P}}$ is the dissociation constant for the ternary enzymesubstrate-inhibitor complex obtained in the presence of the substrate $\mathrm{G} 3 \mathrm{P} ; \mathrm{K}_{\mathrm{i}}^{\mathrm{TNAD}}$ is the dissociation constant for the binary enzyme-inhibitor complex obtained in the presence of the cofactor TNAD; and $\mathrm{K}_{\mathrm{i}}{ }^{\mathrm{TNAD}}$ is the dissociation constant for the ternary enzyme-substrate-inhibitor complex obtained in the presence of the substrate TNAD).

On the basis of the kinetic data collected and to better understand the structural determinants underlying tiliroside binding to TcGAPDH, we conducted co-crystallization assays aimed to obtain a TcGAPDH-tiliroside complex. However, after various attempts to co-crystallize the protein and the inhibitor we could not succeed. This might be related to tiliroside low solubility, because crystals of TcGAPDH were grown and X-ray data collected, nevertheless, the close inspection of the electron density maps did not indicate a blob that could be assigned to the inhibitor molecule. Therefore, aiming at providing molecular insights into TcGAPDH inhibition by tiliroside, we employed molecular modeling approaches to search for potential binding sites and investigate the tiliroside binding mode.

The mechanism of inhibition of tiliroside suggests that its binding site lies in pocket other than the substrate and cofactor binding sites. Hence, we employed SiteHound to identify potential binding cavities in TcGAPDH. SiteHound-web is a web-based tool useful for searching ligand binding sites. The server offers the user the possibility to select molecular probes (i.e., methyl carbon or phosphate oxygen) to map the protein cavities and identify putative binding sites. ${ }^{37}$ Based on computed interactions between a methyl probe and TcGAPDH structure we identified 10 interaction energy clusters corresponding to putative binding sites on the enzyme. The top two scored binding cavities correspond to the binding sites for cofactor and substrate, respectively (Figure 4A). The third best scored binding site is a cavity on the opposite side of the catalytic site (Figure 4A). TcGAPDH is a tetrameric enzyme composed of four identical subunits. ${ }^{38}$ Each monomer has two structural domains, the $\mathrm{NAD}^{+}$- and the 
(A)

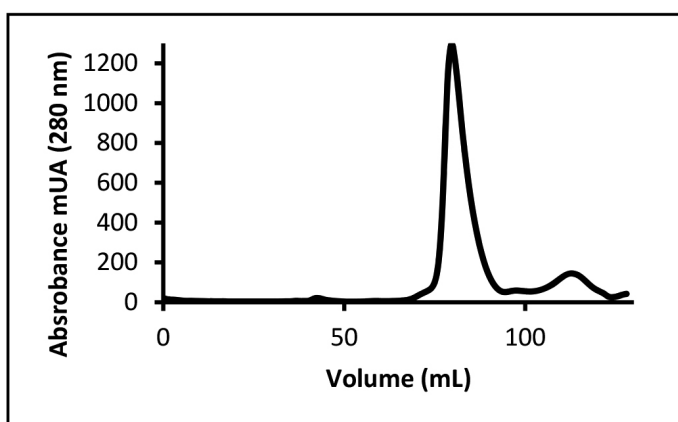

(C)

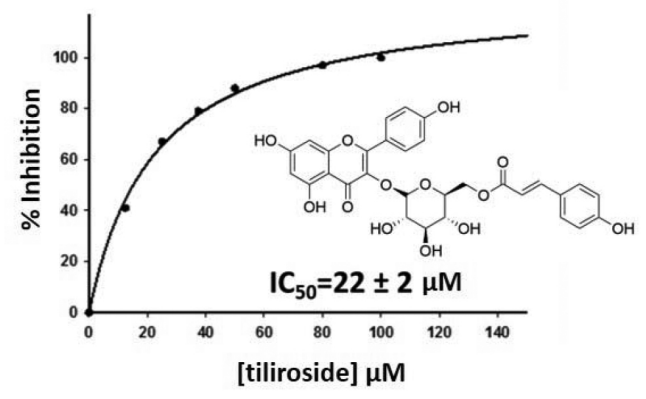

(E)

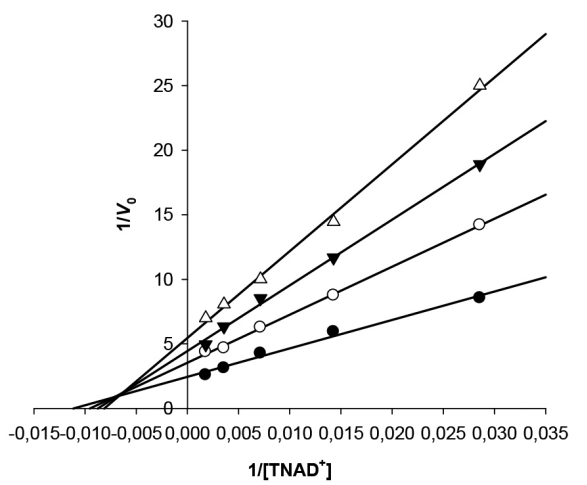

(B)

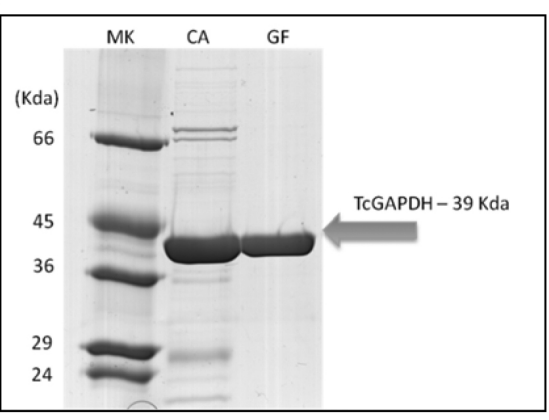

(D)

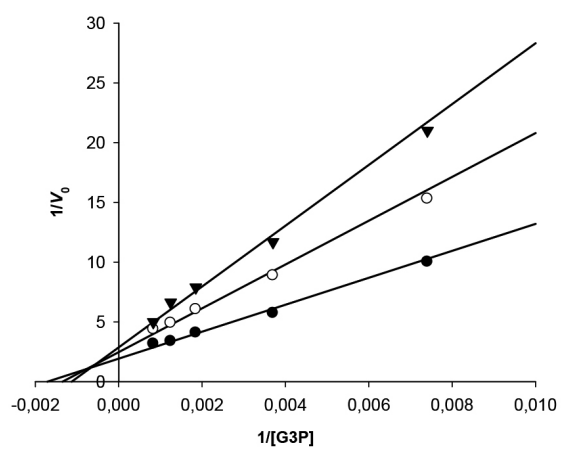

(F)

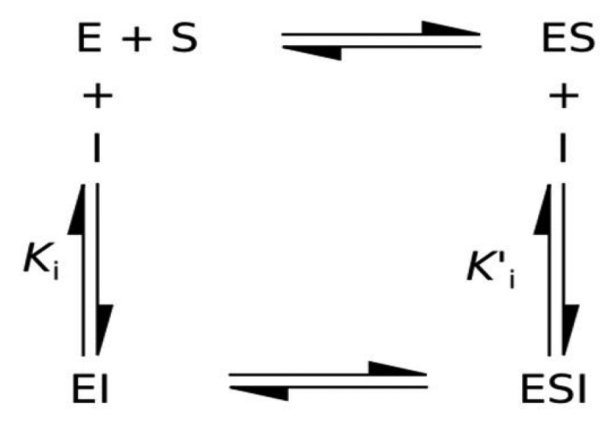

Figure 3. TcGAPDH biochemical investigation. Gel filtration chromatogram (A) and SDS-PAGE (10\%) (B) of purified recombinant TcGAPDH (MK $=$ molecular weight; $\mathrm{AC}=$ affinity column; GF = gel filtration column). Dose-response curve of tiliroside on TcGAPDH activity (C). Non-competitive inhibitory profile of tiliroside in the presence of increasing concentrations of substrate (D) and cofactor (E). Panel D, $5 \mu \mathrm{M}(\mathrm{O}), 10 \mu \mathrm{M}(\boldsymbol{\nabla})$, and absence of inhibitor $(\bullet)$. Panel E, $5 \mu \mathrm{M}(\mathrm{O}), 10 \mu \mathrm{M}(\boldsymbol{\nabla}), 20 \mu \mathrm{M}(\triangle)$ and absence of inhibitor $(\bullet)$. Data were analyzed from three different experiments. (F) Scheme of enzymatic reaction in the presence of non-competitive inhibitor.

catalytic-binding domains.$^{38}$ It is well-known that GAPDHs undergo conformational changes upon $\mathrm{NAD}^{+}$binding. ${ }^{39,40}$ The conformational change can be described as an overall relative rotation of the two domains accompanying the small translation movement of some structural elements. The NAD ${ }^{+}$-binding domain rotates about $6^{\circ}$ relative to the catalytic domain for TcGAPDH (unpublished results).
Similar behavior has been observed for GAPDH from Bacillus stearothermophilus ${ }^{40}$ and Palinurus versicolor. ${ }^{39}$ An examination of the TcGAPDH domain motion indicated that a hinge region can be found between the two domains and close to the third best scored cavity according to SiteHound-web (Figures 4A and 4B). Therefore, due to the structural relevance and favorable interaction energies 
between the binding site residues at the hinge region and the molecular probe, we selected this cavity as a putative binding site for modeling the tiliroside binding mode to TcGAPDH.

The proposed binding mode of tiliroside to TcGAPDH suggests that the inhibitor occupies most of the favorable interaction region of the putative binding site (Figure 2B). In this conformation, tiliroside establishes attractive polar contacts with the TcGAPDH binding site residues. Specifically, the 3-hydroxyl substituent of the $4 H$-chromen4-one ring is hydrogen bonded to the side-chains of Ser352 and His349, while the 5-hydroxyl and 4-hydroxyphenyl substituents are bound to the main-chain carbonyl groups of Tyr284 and Asp345, respectively (Figure 4C). The polar 3-hydroxyl substituent of the tetrahydro- $2 \mathrm{H}$-pyran moiety is in a favorable orientation to accept hydrogen bond from the side-chain of Arg342 and donate hydrogen bond to the side-chain of Asp345. Lastly, the oxygen atom of the ester

(A)

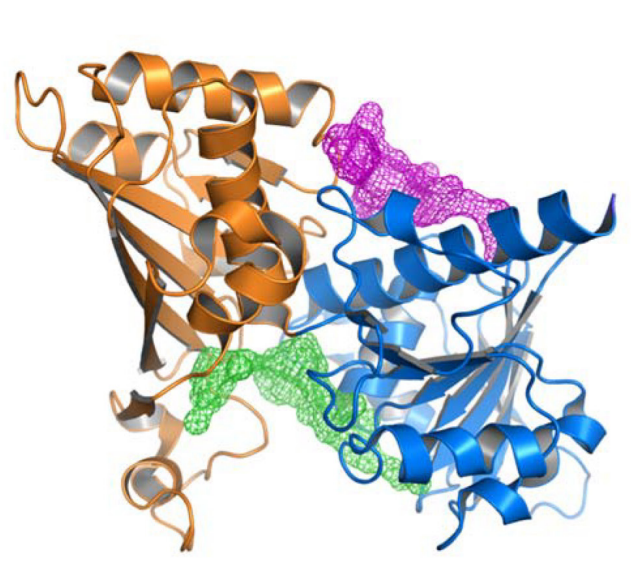

substituent is in close contact to the side-chain of Arg348 and the 4-hydroxyphenyl substituent of the acrylate moiety donates hydrogen bond to the main-chain carbonyl group of Glu23. Moreover, hydrophobic groups of tiliroside make favorable van der Waals contacts with structural elements of the protein to contribute to the complex stability (Figure 4C).

To understand how the binding of tiliroside into the putative binding site inhibits TcGAPDH activity, we propose that the inhibitor binds to the hinge region and freezes the enzyme into an open conformation, thereby preventing TcGAPDH from undergo the conformational change required for catalysis. ${ }^{39,40}$ These findings are in agreement with the kinetic data, which indicate that tiliroside binds to TcGAPDH with higher affinity for the free-form of the enzyme (Figure 3).

Previous studies already demonstrated the isolated tiliroside as TcGAPDH inhibitor. ${ }^{14}$ Freitas et al. ${ }^{14}$
(B)

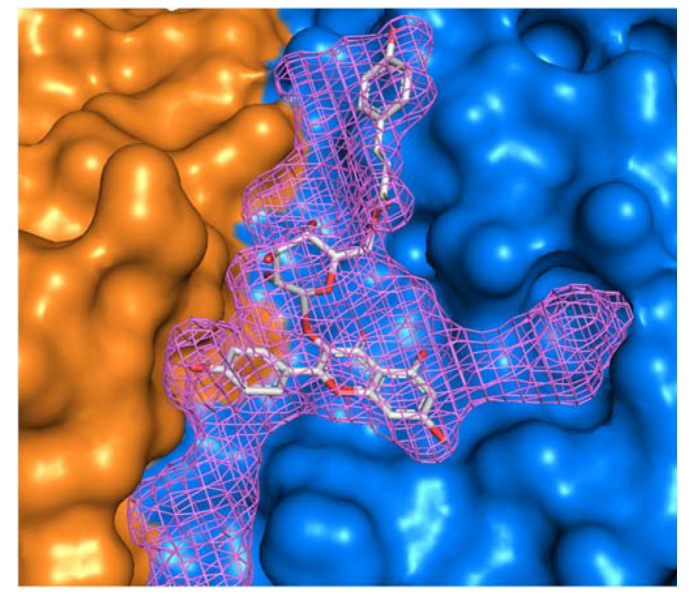

(C)

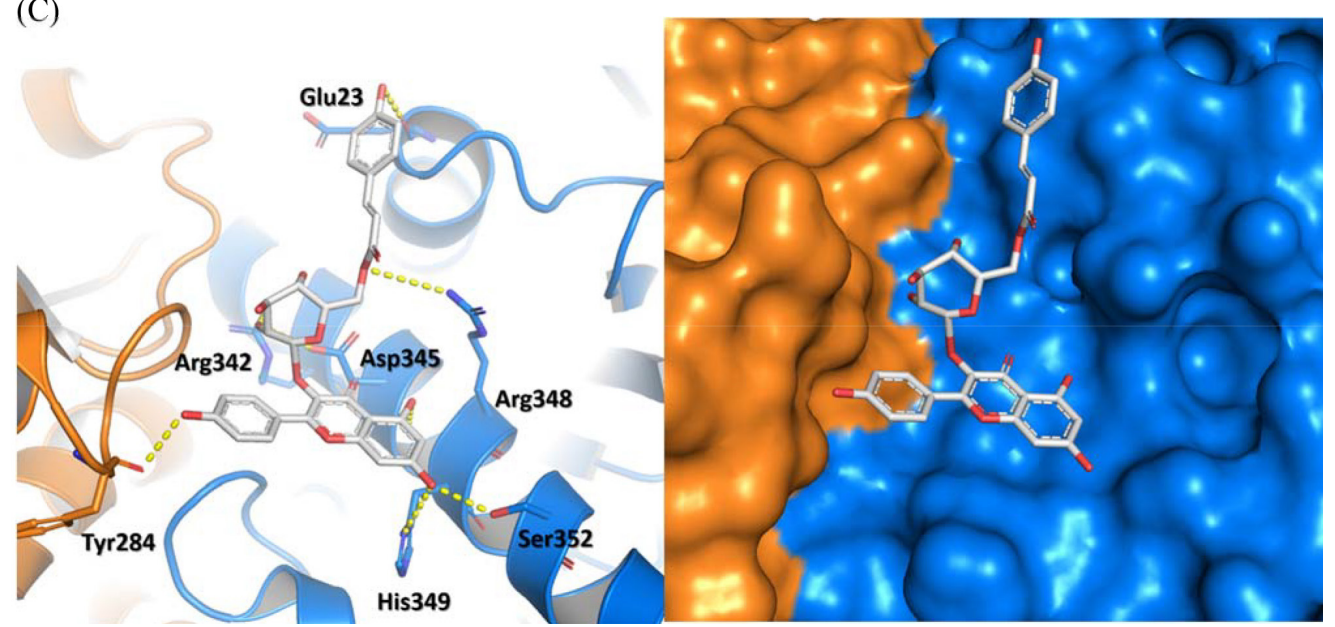

Figure 4. TcGAPDH modeling studies. (A) TcGAPDH subunit (NAD+-binding domain = orange; catalytic-binding domain = blue $)$ and best scored binding sites identified by SiteHound-web (cofactor and substrate binding sites = green mesh; hinge region site = magenta mesh); (B) modeled binding mode of tiliroside (white sticks) into TcGAPDH cavity envelope (upper panel - magenta mesh) at the hinge region (lower panel); (C) detailed view of tiliroside modeled binding mode to TcGAPDH (hydrogen bonds = yellow dashes). 
determined the potency of several natural products against the enzyme, and the tiliroside was one of the most promising inhibitor with activity in the micromolar range $\left(\mathrm{IC}_{50}\right.$ value of $\left.46 \mu \mathrm{M}\right)$. The study did not investigate the mechanism of inhibition, however, molecular modeling analysis suggested that the tiliroside binds to the catalytic site. In this work, the mechanism of inhibition indicated that tiliroside is a non-competitive inhibitor of TcGAPDH with respect to both the substrate and cofactor, thereby suggesting that its binding site lies in pocket other than the substrate and cofactor binding sites.

It is important to mention that although it is not possible to co-crystallize GAPDH and tiliroside it was proved the reversible non-competitive inhibition mode by reliable assays and the molecular modeling approaches was effectively employed to search for potential binding sites and investigate the tiliroside binding mode.

\section{Conclusions}

The bioactivity-guided TcGAPDH assay proved to be an efficient method to find new inhibitors in complex matrices, such as crude extracts of plants. Among assays of several crude extracts of plants, the discovery of tiliroside from Spiranthera odoratissima, first time reported in this specie, as TcGAPDH inhibitor in a great diversity of secondary metabolites and the identification of a new binding site in TcGAPDH pave the way to the discovery of new non-competitive inhibitors as lead candidates for drug development.

\section{Supplementary Information}

Supplementary information (inhibition of crude extracts of plants against TcGAPDH, ${ }^{1} \mathrm{H},{ }^{13} \mathrm{C}, \mathrm{COSY}, \mathrm{HSQC}$ and HMBC NMR experiments of tiliroside) is available free of charge at http://jbcs.sbq.org.br as PDF file.

\section{Acknowledgments}

The authors gratefully acknowledge financial support from FAPESP (The State of São Paulo Research Foundation, grants No. 2009/17538-8 and No. 2013/07600-3), CAPES and the National Council for Scientific and Technological Development (CNPq), Brazil.

\section{References}

1. Aufderheide, A. C.; Salo, W.; Madden, M.; Streitz, J.; Buikstra, J.; Guhl, F.; Arriaza, B.; Renier, C.; Wittmers Jr., L. E.; Fornaciari, G.; Allison, M.; Proc. Natl. Acad. U. S. A. 2004, 101, 2034.
2. Coura, J. R.; Borges-Pereira, J.; Acta Trop. 2010, 115, 5.

3. Coura, J. R.; Castro, S. L.; Mem. Inst. Oswaldo Cruz 2002, 97, 3.

4. WHO, http://www.who.int/mediacentre/factsheets/fs340/en/, accessed in September 2016.

5. Filardi, L. S.; Brener, Z.; Trans. R. Soc. Trop. Med. Hyg. 1987, 81, 755 .

6. Urbina, J. A.; Acta Trop. 2010, 115, 55.

7. Song, S. W.; Finkel, T.; Nat. Cell Biol. 2007, 9, 869.

8. Caceres, A. J.; Michels, P. A. M.; Hannaert, V.; Mol. Biochem. Parasitol. 2010, 169, 50.

9. Barros-Alvarez, X.; Gualdron-Lopez, M.; Acosta, H.; Caceres, A. J.; Graminha, M. A. S.; Michels, P. A. M.; Concepcion, J. L.; Quinones, W.; Curr. Med. Chem. 2014, 21, 1679.

10. Ganapathy-Kanniappan, S.; Geschwind, J. F. H.; Mol. Cancer 2013, 12, 152.

11. Guido, R. V. C.; Castilho, M. S.; Mota, S. G. R.; Oliva, G.; Andricopulo, A. D.; QSAR Comb. Sci. 2008, 27, 768.

12. Pavao, F.; Castilho, M. S.; Pupo, M. T.; Dias, R. L. A.; Correa, A. G.; Fernandes, J. B.; da Silva, M.; Mafezoli, J.; Vieira, P. C.; Oliva, G.; FEBS Lett. 2002, 520, 13.

13. Vieira, P. C.; Mafezoli, J.; Pupo, M. T.; Fernandes, J. B.; da Silva, M.; de Albuquerque, S.; Oliva, G.; Pavao, F.; Pure Appl. Chem. 2001, 73, 617.

14. Freitas, R. F.; Prokopczyk, I. M.; Zottis, A.; Oliva, G.; Andricopulo, A. D.; Trevisan, M. T. S.; Vilegas, W.; Silva, M. G. V.; Montanari, C. A.; Bioorg. Med. Chem. 2009, 17, 2476.

15. Leitao, A.; Andricopulo, A. D.; Oliva, G.; Pupo, M. T.; de Marchi, A. A.; Vieira, P. C.; da Silva, M.; Ferreira, V. F.; de Souza, M.; Sa, M. M.; Moraes, V. R. S.; Montanari, C. A.; Bioorg. Med. Chem. Lett. 2004, 14, 2199.

16. Herrmann, F. C.; Lenz, M.; Jose, J.; Kaiser, M.; Brun, R.; Schmidt, T. J.; Molecules 2015, 20, 16154.

17. Bruno, S.; Pinto, A.; Paredi, G.; Tamborini, L.; De Micheli, C.; La Pietra, V.; Marinelli, L.; Novellino, E.; Conti, P.; Mozzarelli, A.; J. Med. Chem. 2014, 57, 7465.

18. Bruno, S.; Margiotta, M.; Pinto, A.; Cullia, G.; Conti, P.; De Micheli, C.; Mozzarelli, A.; Bioorg. Med. Chem. 2016, 24, 2654.

19. Newman, D. J.; Cragg, G. M.; J. Nat. Prod. 2016, 79, 629.

20. Cornelio, V. E.; Pedroso, M. M.; Afonso, A. S.; Fernandes, J. B.; da Silva, M. F. G. F.; Faria, R. C.; Vieira, P. C.; Anal. Chim. Acta 2015, 862, 86.

21. de Sousa, L. R. F.; Ramalho, S. D.; Burger, M. C. D.; Nebo, L.; Fernandes, J. B.; da Silva, M.; Iemma, M. R. D.; Correa, C. J.; de Souza, D. H. F.; Lima, M. I. S.; Vieira, P. C.; J. Nat. Prod. 2014, 77, 392.

22. Galdino, P. M.; Nascimento, M. V. M.; Florentino, I. F.; Lino, R. C.; Fajemiroye, J. O.; Chaibub, B. A.; de Paula, J. R.; de Lima, T. C. M.; Costa, E. A.; Prog. Neuro-Psychopharmacol. Biol. Psychiatry 2012, 38, 276.

23. Barbosa, D. B. M.; Nascimento, M. V. M.; Lino, R. C.; Magalhaes, M. R.; Florentino, I. F.; Honorio, T. C. D.; Galdino, 
P. M.; Bara, M. T. F.; de Paula, J. R.; Costa, E. A.; Braz. J. Pharmacog. 2012, 22, 137.

24. Matos, L. G.; Pontes, I. S.; Tresvenzol, L. M. F.; Paula, J. R.; Costa, E. A.; Phytother. Res. 2004, 18, 963.

25. Albernaz, L. C.; de Paula, J. E.; Romero, G. A. S.; Silva, M. D. R.; Grellier, P.; Mambu, L.; Espindola, L. S.; J. Ethnopharmacol. 2010, 131, 116.

26. Dos Santos, R. A. N.; Batista, J.; Rosa, S. I. G.; Torquato, H. F.; Bassi, C. L.; Ribeiro, T. A. N.; De Sousa, P. T.; Bessera, A.; Fontes, C. J. F.; Da Silva, L. E.; Piuvezam, M. R.; Parasitology 2011, 138, 1224.

27. Terezan, A. P.; Rossi, R. A.; Almeida, R. N. A.; Freitas, T. G.; Fernandes, J. B.; da Silva, M.; Vieira, P. C.; Bueno, O. C.; Pagnocca, F. C.; Pirani, J. R.; J. Braz. Chem. Soc. 2010, 21, 882.

28. Freitas, C. M. D.; Lucchese, A. M.; Silva, F. S.; Velozo, E. D.; Biochem. Syst. Ecol. 2003, 31, 805.

29. Ribeiro, T. A. N.; Ndiaye, E. A. D.; Velozo, E. D.; Vieira, P. C.; Ellena, J.; de Sousa, P. T.; J. Braz. Chem. Soc. 2005, 16, 1347.
30. Tsukamoto, S.; Tomise, K.; Aburatani, M.; Onuki, H.; Hirorta, H.; Ishiharajima, E.; Ohta, T.; J. Nat. Prod. 2004, 67, 1839.

31. Aslanidis, C.; Dejong, P. J.; Nucleic Acids Res. 1990, 18, 6069.

32. Gasteiger, E.; Gattiker, A.; Hoogland, C.; Ivanyi, I.; Appel, R. D.; Bairoch, A.; Nucleic Acids Res. 2003, 31, 3784.

33. Maluf, F. V.; Andricopulo, A. D.; Oliva, G.; Guido, R. V. C.; Future Med. Chem. 2013, 5, 2019.

34. Guido, R. V. C.; Balliano, T. L.; Andricopulo, A. D.; Oliva, G.; Lett. Drug Des. Discovery 2009, 6, 210.

35. McGovern, S. L.; Helfand, B. T.; Feng, B.; Shoichet, B. K.; J. Med. Chem. 2003, 46, 4265.

36. Saint-Hilaire, A. F. C. P.; Bull. Soc. Philom. Paris 1823, available at http://floradobrasil.jbrj.gov.br/jabot/floradobrasil/FB1023, accessed in September 2016.

37. Hernandez, M.; Ghersi, D.; Sanchez, R.; Nucleic Acids Res. 2009, 37, W413.

38. Souza, D. H. F.; Garratt, R. C.; Araújo, A. P. U.; Guimarães, B. G.; Jesus, W. D. P.; Michels, P. A. M.; Hannaert, V.; Oliva, G.; FEBS Lett. 1998, 424, 131.

39. Shen, Y. Q.; Li, J.; Song, S. Y.; Lin, Z. J.; J. Struct. Biol. 2000, $130,1$.

40. Skarzynski, T.; Wonacott, A. J.; J. Mol. Biol. 1988, 203, 1097.

Submitted: October 14, 2016

Published online: December 7, 2016 